\title{
Quem paga o impacto? Considerações sobre conflitos de interesses
}

Encontrei em meu escaninho um texto com uma foto de um jogo de xadrez. Por achar que se tratava de mais um das centenas de folhetos indesejáveis que proliferam por geração espontânea nas caixas de correspondência, já ia jogando o texto fora quando seu título me chamou a atenção: "The politics of publication". ${ }^{1}$

$\mathrm{O}$ artigo abordava uma série de aspectos vinculados à publicação em revistas científicas, um tema particularmente oportuno neste momento em que, mundialmente, a quantidade de trabalhos publicados em revistas de alto índice de impacto passou a ser sinônimo de qualidade científica. E, mais do que isso, no meio acadêmico, tais parâmetros bibliométricos passaram a ter o poder de gerar recursos para pesquisa, facilitar a conquista de posições e impulsionar a carreira do autor.

Um levantamento realizado por Leopoldo de Méis, do Instituto de Ciências Biomédicas da UFRJ, divulgado em conferência proferida no Instituto de Estudos Avançados na USP, em abril de 2003, ilustra bem como isso ocorre no Brasil: em um dos comitês de avaliação do CNPq foram solicitados 437 auxílios, dos quais 267 atingiram os atributos de mérito. Como os recursos eram suficientes apenas para 20 deles, os critérios adotados levaram em consideração, principalmente, o número de publicações e o impacto das revistas onde o solicitante publicou.

A pressão para publicar é cada vez maior nessa ditadura da contabilidade, enquanto a efetiva contribuição científica é cada vez menos avaliada. As consequiências não poderiam ser mais perversas: bons trabalhos são subdivididos para produzir mais papers, uma única informação é duplicada com a mesma finalidade e, muitas vezes, um paper é submetido à avaliação prematuramente, levando à necessidade de um segundo paper para corrigir os erros do primeiro.

Nesse cenário, o que é determinante na decisão do que vai ou não ser publicado? De um lado, editores buscam atrair os leitores com assuntos "da moda", polêmicos ou assinados por autores de prestígio. De outro, os revisores muitas vezes se vêem pressionados por questões como o que fazer com o trabalho que apresenta resultados opostos às suas próprias publicações ou, pior, que apresenta afinidades que tirariam o caráter inédito de seus achados se fosse publicado primeiro.

E isso nos faz questionar o quão isentas de "conflito de interesses" são as publicações. O termo é abrangente e aplica-se às potenciais fontes de vieses que podem comprometer a credibili- dade ou a integridade de pesquisas científicas e sua divulgação.

Os interesses secundários podem ser de todos os tipos - pessoais, políticos, ideológicos, acadêmicos (pressões de produtividade, rivalidade, desejo de reconhecimento profissional e outros) -, porém, mais freqüentemente, são mesmo financeiros.

Em todas as áreas da Medicina, cada vez mais, a pesquisa científica conta com financiamento de indústrias farmacêuticas. Esta é uma aliança necessária e valiosa. Não importa que os interesses das indústrias sejam puramente comerciais quando seu financiamento pode determinar reais avanços no tratamento e prevenção das doenças. Entretanto, quando os resultados são desfavoráveis, os conflitos podem se manifestar. Aparentemente estudos financiados pelas indústrias têm maior probabilidade de relatar resultados favoráveis a seus produtos do que os independentes. Friedberg et $\mathrm{al}^{2}$ encontraram resultados desfavoráveis em 5\% dos estudos financiados pelos laboratórios produtores de drogas utilizadas em oncologia. Já em estudos independentes, essa taxa subiu para $38 \%$.

Alguns ponderam que vieses sistemáticos nos resultados não significam que a pesquisa patrocinada seja de má qualidade, mas sim que as questões científicas foram formuladas de forma a refletir os interesses dos patrocinadores. No entanto, em pesquisas financiadas por laboratórios, não há o que justifique a existência de contratos com cláusulas restritivas à publicação de resultados indesejáveis ou negativos. Por exemplo, um artigo da revista Science $^{3}$ chama a atenção para uma pesquisa hematológica desenvolvida no Canadá que identificou riscos inesperados associados à droga. Porém, o laboratório que a produzia e financiava a pesquisa, baseado nas cláusulas de confidencialidade, impediu que seus resultados fossem comunicados aos pacientes ou divulgados em artigos científicos.

Como essas questões aparentemente mais acadêmicas interessam ao clínico? A falta de tempo faz com que, para atualização, o médico leia artigos de revisão e metanálise. Entretanto, esses estudos precisam ser interpretados com cautela, pois se baseiam em artigos publicados e convém lembrar que estudos com resultados significativos são mais facilmente publicados do que aqueles com resultados negativos. Ou, ainda, que suplementos de revistas publicam como full paper pesquisas que são apresentadas em congressos sem passar pela análise de assessores. 
De fato, os vieses de publicação têm implicações consideráveis na prática clínica. As Clinical Practice Guidelines são elaboradas com a finalidade de apresentar uma síntese das evidências e recomendações atuais dos especialistas clínicos de uma determinada área. Uma pesquisa que quantificou a natureza e a extensão de interações entre autores destas diretrizes e a indústria farmacêutica ${ }^{4}$ mostrou que $87 \%$ dos autores tinham alguma forma de interação com a indústria, 58\% receberam apoio financeiro para realizar pesquisas e $38 \%$ haviam sido empregados de indústrias ou seus consultores.

Algumas medidas já estão sendo tomadas no sentido de proteger os interesses dos pesquisadores e dos laboratórios. Recentemente foram publicadas normas específicas para publicação de estudos financiados por indústrias farmacêuticas. ${ }^{5} \mathrm{~A}$ declaração de interesses que vem sendo adotada por algumas revistas tem sido alvo de debate entre os defensores da medida e os que a apontam como invasiva e excessivamente controladora. Para estes últimos, a transparência pode resultar facilmente em preconceito injustificado.

Como felizmente para mim este não é um artigo científico, não preciso finalizá-lo com conclusões, que neste caso não são simples, nem diretas. Mas espero que seu conteúdo tenha produzido impacto suficiente para que você, caro leitor, sinta-se estimulado a refletir sobre o assunto.

Clarice Gorenstein

Departamento de Farmacologia, Instituto de Ciências Biomédicas, Universidade de São Paulo. São Paulo Laboratório de Psicofarmacologia, Instituto de Psiquiatria,

HC-FMUSP. São Paulo

\section{Referências}

1. Lawrence PA. The politics of publication. Nature 2003;422:259-61.

2. Friedberg M, Saffran B, Stinson TJ, Nelson W, Bennett CL. Evaluation of conflict of interest in economic analyses of new drugs used in oncology. JAMA 1999;282:1453-7.

3. Baird P, Downie J, Thompson J. Clinical trials and industry. Science 2002;297:2211.

4. Choudhry NK, Stelfox HT, Detsky AS. Relationships between authors of clinical practice guidelines and the pharmaceutical industry. JAMA 2002;287:612-7.

5. Wagner E, Field EA, Grossman L. Good publication practice for pharmaceutical companies. Curr Med Res Opin 2003;19:149-54. 